\title{
Türk Futbol Kültürünün Küreselleşme Kavram ve Süreçleri Bağlamında Değerlendirilmesi
}

\author{
Muhammet Nurullah Çakmak, Mahmut Sami İșlek, Uğur Keskin \\ Anadolu Üniversitesi, Spor Bilimleri Fakültesi, mncakmak@anadolu.edu.tr \\ Anadolu Üniversitesi, Sosyal Bilimler Enstitüsü, msislek@anadolu.edu.tr \\ Anadolu Üniversitesi, İşletme Fakültesi, ugurkeskin@anadolu.edu.tr
}

\begin{abstract}
Özet
Küreselleşme, çağımızın en görünür ve en popüler alanlarından birini oluşturmaktadır. Ekonomik, sosyal, siyasi tarafi çokça tartışılmış, birçok araştırmaya yer verilmiştir. Kültürel alan ise en az ekonomik ve siyasal alan kadar önemli olmasına rağmen kısmen ihmal edilmiştir. Roland Robertson bu noktadaki eksikliğe dikkat çekerek, küreselleşmenin kültürel boyutunu merkeze alan çalışmalar yapmış ve en çok bilinen kavramı, küyerelleşmeyi geliştirmiştir. Daha sonra Richard Giulianotti ile birlikte dünyanın en küresel formlarından biri olan futbol ve kültürünü, küyerelleşme bağlamında değerlendirmişlerdir. Bu çalışmada Robertson ve Giulianotti’nin küresel futbol kültürüne yaklaşımları referans alınarak, Türk futbol kültürü evrensellik-tikellik, homojenleşme-heterojenleşme-melezleşme,küyerelleşme ve küresel süreçler bağlamında değerlendirilmiştir. Literatür incelendiğinde Türk futbolu ve küreselleşme ilişkisini ele alan çalışmalara rastlamak mümkündür. Ancak kültürel boyutunun incelendiği çalışmaların eksik olduğu gözlenmiştir. Çalışmamızın temel amacı Türk futbol kültürünün küreselleşme ile olan ilişkisini, küyerelleşme kavramı çerçevesinde, merkez-çevre ilişkisinin asimetrik akış niteliğini de dikkate alarak değerlendirmektir.
\end{abstract}

Anahtar Kelimeler: Küreselleşme, Küyerelleşme, Futbol, Türk Futbol Kültürü.

\section{An Evaluation of Turkish Football Culture in Terms of Globalization Concepts and Processes}

\section{Abstract}

Globalization is one of the most visible and popular areas of our age. The economic, social and political sides of it have been widely discussed and many researches have been included. Even though the cultural field is at least as important as the economic and political space, it is partially neglected. Roland Robertson has focused on the cultural dimension of globalization by drawing attention to the shortcoming at this point, and has developed the most familiar concept; glocalization. Then, with Richard Giulianotti, they evaluated football and culture, one of the most global forms of the world, in the context of glocalization. With reference to Robertson and Giulianotti's approaches to global football culture, this study examined Turkish football culture in terms of universality-particularity, homogenization-heterogenizationhybridization, glocalization and global processes. When literature is examined, it is possible to come across studies that deal with the relationship between Turkish football and globalization. However, it has been observed that the studies examining the cultural dimension are lacking. The main purpose of our study is to evaluate the relation of Turkish football culture and globalization, with taking into account the asymmetric flow characteristics of the center-periphery relation, in the framework of the glocalization concept.

Keywords: Globalization, Glocalization, Football, Turkish Football Culture.

\section{Giriş}

Küreselleşme konusu, 1990'ların özellikle ikinci yarısından sonra popülerlik kazanmış ve nihayet 2000'li yılların en çok konuşulan kavramlarının başında yer almaya başlamıştır. Teknolojinin baş döndürücü hızda gelişmesi, çok uzun mesafeleri çok kısa sürede kat eden ulaşım araçlarının geliştirilmesi, dünyanın en uzak noktalarındaki insanların bile birbirleriyle anlık olarak haberleşecekleri iletişim sistemlerinin icad, ekonomik krizlerin artık sadece bulundukları ülkeleri değil dünyanın önemli bir kısmını kısa sürede etkilemesi gibi gelişmeler sosyal bilimcileri yaşadıkları dünyayı geçmiş dönemlerden ayırma gereksinimine yönlendirmiştir.

Küreselleşme kavramı, sosyal bilimlerdeki güncel kavramlarla simbiyotik (ortak yaşam) biçimde ilişkiye girmektir. Ekonomi, terör, teknoloji, ulaşım, iletişim gibi unsurların tek başına ifade edilebilmelerinin olanağı ortadan kalkmış, bunun yerine; küresel ekonomi, küresel terör, küresel teknoloji gibi kavramsallaştırmalara gitme zorunluluğu ortaya çıkmıştır. Küreselleşme kavramı, sosyal bilimlerde yerleşik bir kavram haline gelmiş ve sıklıkla kullanılır olmuştur. Buna karşın, küreselleşmeden ne anlaşıldığı konusunda tam anlamıyla bir uzlaşı sağlanmış da değildir.

Küreselleşme yaklaşımlarının vurguları, genellikle ekonomi temelli olarak ortaya çıkmıştır. Kültürün küreselleşme süreci içindeki durumu, ekonomiden daha sonra fark edilmiştir. Tam bu noktada Roland Robertson (1999), küreselleşmenin salt ekonomi temelli olmadığını, kültürel boyutunun da en az ekonomi kadar önemli olduğunu israrla vurgulamıştır. Küreselleşmenin tek başına yerel kültürleri yok ettiği, çatışmacı bir anlayışın yerine; küreselliğin yerel olanı dikkate aldığı, etkilediği ve yerel olandan etkilendiğini gösteren küyerelleşme (glokalaleşme) kavramını önermiştir. Hem tikellik ile farklılığa hem de evrensellik ile türdeşliğe doğrudan ve dengeli bir ilgiyle yaklaşmak gerektiğini ileri 
sürmüştür. Roberson'un temel savı “yirminci yüzyılın sonlarında tikelciliğin evrenselleşmesi ve evrenselciliğin tikelleşmesinin iç içe geçmesini kapsayan derin, ikili bir sürece" girilmiş olduğu yönündedir (Robertson, 1999).

\section{2. Çalışmanın Amacı ve Önemi}

Çalışmamızın temel amacı Türk futbol kültürünü, küreselleşmenin kültürel boyutu bağlamında değerlendirmektir. $\mathrm{Bu}$ noktada küreselleşmenin kültürel boyutunu merkeze alan ilk çalışmaları gerçekleştiren Roland Robertson'ın küreselleşme ve kültür kuramı temel alınmıştır. Türkçe literatürde küreselleşmenin spor ya da futbol özelindeki ilişkisini konu edinen birçok çalışma bulunmaktadır (Ekmekçi vd., 2013; Atasoy ve Kuter, 2005; Akkaya, 2008; Öngören ve Karadoğan, 2002; Talimciler, 2008; Sen, 2013; Özkan, 2011). Ancak küreselleşme bakış açısıyla Türk futbol kültürünü karşılıklı ilişki kuran, evrenseltikel etkileşimiyle yeni kültürel formlar bağlamında değerlendiren herhangi bir çalışma bulunmamaktadır. Söz konusu eksiklik, bu çalışmanın özgün yönünü teşkil etmektedir.

\section{Kavramsal Çerçeve}

Küreselleşme kavramı -özellikle son yirmi yıldapopülaritesini arttırmıştır. Ekonomiden siyasete, akademik tartışmalardan kültüre ve günlük yaşama kadar birçok konuyu etkileyen, değiştiren, dönüştüren bir süreç olarak belirginlik kazanmıştır. Söz konusu niteliği nedeniyle de üzerinde çok sayıda yazı yazılmış, araştırma ve incelemeler yapılmıştır. $\mathrm{Bu}$ çalışmada, küreselleşmenin, futbol endüstrisine olan yansımaları çeşitli yönleriyle ele alınmıştır. Çalışmanın kavramsal ve kuramsal çerçevesi, aşağıdaki anlatım başlıkları altında sırasıyla açıklanmıştır.

\subsection{Küreselleşme Kavramı}

Yalın ve kapsayıcı bir tanıma göre "Küreselleşme, pratiklerin, bilincin, toplumsal yaşamın dünya ölçeğine yayılmasıdır". Hemen hemen her ulus ve insan topluluğu, küreselleşme tarafından çarpıcı bir biçimde dönüştürülmektedir (Ritzer ve Stepnisky, 2014: 581).

Küresel çapta meydana gelen bu dönüşüm/ değişim/ benzeşim sosyal bilimciler tarafindan çeşitli yönlerde ele alınmıştır. Kimilerine göre dünyanın denetimden çıkması (Giddens, 2000), kimilerine göre kapitalizmin uluslararası hâkimiyetinin, hegemonyasının, sömürüsünün yeni adı (Beck, 2000; Klein, 2002), kimilerine göre ise merkezi olmayan yeni tür bir imparatorluktur (Harth ve Negri, 2001).

Her kavram ya da teorinin bilimsel yönünün yanı sıra, ideolojik bir yöne de sahip olduğu hususu, yaygın kabul görmüş bir gerçekliktir. Bu bakımdan küreselleşme olgusu bir yandan yaşanılan dünyanın tecrübe ettiği ciddi dönüşümleri açıklamak üzere geliştirilmiş bir kavram olmasının yanında, muhtevasında örtülü birtakım telkin ve yönlendiriciliği de barındırmaktadır. Kuşku uyandıran ve üzerinde uzlaşma sağlanan bir tanımdan yoksun olmasına rağmen küreselleşme, modern dünyada oldukça güçlü ve kapsamlı süreçlerden biri olarak algılanmaktadır. Söz konusu algıdan kaynaklanan popülerliği sayesinde, önüne geçilemeyen ve durdurulamayan bir eğilim olarak ifade edilmeye başlamıştır. Küreselleşmenin 90'lı yıllarda sosyal bilimler alanında giderek artan bir şekilde etkili bir konuma sahip olmasının altında, kısmen modernleşme perspektifinin, bu gibi olguları açıklamadaki yetersizliğinin ve söz konusu olgunun, modernleşmenin yetersiz kaldığ 1 düşünülen sorunları çözebilme izlenimi vermesinden, kısmen de dönemin ruh halini yansıtmasının ve bir moda eğilim olarak kendisini cazip hale getirmesinden kaynaklandığını ileri sürmek mümkün görünmektedir (Bodur, 2004:11).

Küreselleşme kelimesinin literatürdeki çağdaş anlamıyla yer alması, Marshall McLuhan'ın "küresel köy” kavramının kullanması ile olmuştur. McLuhan'a göre elektronik araçlarındaki gelişmeler, iletişimde zaman-mekân sınırlarını ortadan kaldırarak dünyayı "küresel bir köye" dönüştürecektir (Cebeci, 2011:362).

Küreselleşme çeşitli şekillerde tanım bulmuştur. Örneğin Jacques Adda'ya göre "küreselleşmeden söz etmek, iktisadi bir sistem olan kapitalizmin dünyaya yayıldığını söylemektir" (Adda, 2005:9). Bauman'a göre ise, "küreselleşme hem dönüşü olmayan hem de hepimizi aynı ölçüde ve aynı şekilde etkileyen bir süreç; dünyanın kaçınılmaz kaderidir" (Bauman, 2010:7).

Küreselleşme, yerel-evrensel spektrumunda her iki yöne doğru ilerleyen bir süreci tarif etmekte, statik bir yapıdan ziyade son derece dinamik ve değişken bir kavrama işaret etmektedir. Küreselleşme, her geçen gün dünyanın farklı alanlarını nüfuzu altına almaya devam etmekte ve bu sayede bünyesine kattığı yeni açılım ve devinimler ile mevcut yapısını sürekli bir biçimde uyarlamaktadır (Bayar, 2008:25).

\subsection{Küreselleşmeyi Etkileyen Faktörler}

İnsanlığın geçirmiş olduğu tecrübeler; yeni kavramların, olguların, olayların, soyut ve somut sonuçların doğduğu bir dizi gelişmelerle şekillenmiştir. Bir önceki gelişmelerin sonucu bir sonraki gelişmelerin nedeni olmuş, zincirin halkaları şeklinde günümüze ulaşmıştır. Küreselleşmenin ortaya çıkışı da bu zincire yeni eklenen halkalar vasıtasıyla gerçekleşmiştir. $\mathrm{Bu}$ bağlamda küreselleşmeyi etkileyen en temel faktörleri şu şekilde sıralamak mümkündür (Giddens, 2000: 2012):

Bilgi ve İletişim Teknolojilerindeki Gelişmeler: Küresel iletişimdeki patlama, teknoloji ile dünyanın telekomünikasyon altyapısındaki bir dizi önemli ilerleme tarafından kolaylaştırılmıştır. İletişim teknolojisinin bu denli ilerlemesi ve yayılması, önceleri çok sınırlı olan bilgi akışını çok daha ucuz ve hızlı hale getirmiştir. Telgraf, mektup gibi iletişim araçlarının yerini bugün çok daha hızlı ve çok daha kapsamlı teknikler almıştır. Dünyanın bir ucundan diğerine neredeyse ücretsiz olarak anında görüşme, iletişim kurabilme imkânı sağlanmaktadır. İlk ticari uydu 1969 yılında uzaya gönderildi ve bugün uydu sayısı 200'ü geçmiş durumdadır. 1950'lerde Atlantik ya da Pasifik'i geçen tek bir kablo yokken bugün milyonlarca kablo döşenmiştir.

Ekonomik Etkenler:Küreselleşme aynı zamanda dünya ekonomisinin bütünleşmesi ile de yönlendirilmektedir. Geçmiş dönemlerin tarım ya da sanayi gibi ticari materyallerinin yerini bugün somut olmayan, elektronik ortamlarda üretilip dağıtılan ticari materyaller almıştır. Bu da ticaretin çok daha hızlı olması ve geniş alana yayılmasını sağlamıştır. $\mathrm{Bu}$ yayılmayı ulusaşırı şirketler üstlenmişlerdir. Ulusaşırı şirketler birden fazla ülkede mal ya da hizmet üreten, pazarlayan kurumlardır. Bunların en bilinenleri Coca Cola, McDonalds, Levis, City Bank, Nike, Adidas gibi kuruluşlardır. 
Politik Değișmeler: Küreselleşmeyi etkileyen en önemli siyasi gelişme kuşkusuz Sovyetler Birliğinin yıkılması ile içine kapanık komünist rejimin yıkılması ve nihayetinde Doğu Bloğu ülkelerin yapılarını liberal șekle dönüştürmeleridir. Sovyet rejiminin çökmesi ile birlikte küreselleşmenin -tam olarak- nüfuz edemediği bölgeler de artık küresel etkiye açık hale gelmiştir. Ekonomik, kültürel, toplumsal değişmelerin önünde engel olan siyasi rejim değişmiş ve komünist ülkeler de etkileşim alanına girmişlerdir.

\subsection{Küreselleşme Yaklaşımları}

Küreselleşme kavramı; ideolojiler, dünya görüşü, yaşam şartları gibi konulara göre değişiklik göstermektedir. Kimilerine göre küreselleşme kavramı sömürünün yeni adı ve kapitalizmin yeni oyunuyken; kimilerine göre insanlığı dünya cennetine ulaştıracak, dünyanın tamamını çağdaşlaştırıp modernleştirecek sihirli bir anahtardır. Kimileri ise bu süreci bir değişim ve dönüşüm süreci olarak görmektedir.

Kuşkucular (Gelenekçiler): Kuşkucu çizgisinde bulunanlara göre küreselleşme; gelişmiş ülkelerin kendi ekonomik, siyasal ve kültürel yapılarını az gelişmiş ya da gelişmekte olan ülkelere empozeetme uğraşısı olarak değerlendirilmektedir (Bodur, 2004:11).Bu grubun düşünürleri denince ilk akla gelenler, NaomiKlein, Noreena Hertz, Paul Hirst, GrahamThompson, Joseph Stiglitz gibi küreselleşmeyi büyük ölçüde eleştirenlerdir (Cebeci, 2011:371).

Aşırı Küreselleşmeciler: $\mathrm{Bu}$ grup, küreselleş̧meyi sonuna kadar desteklemekte ve bu sürecin dünya ölçeğinde daha da derinleşip genişlemesi gerektiğini ileri sürmektedirler. $\mathrm{Bu}$ görüşe göre ulus devletler artık geçerliliğini kaybetmiş ve anakronik bir yapıya dönüşmüşlerdir. Ulus devletlerin yerini uluslararası şirketler alacak ve denetimi onlar sağlayacaktır. $\mathrm{Bu}$ anlamda ulus devletin sonunun geldiği ileri sürülmektedir. Bu nedenle, küresel olarak entegre olan piyasalar, ulus-devletin ekonomik işlevlerini devralmaktadırlar. Aşırı küreselleşmeci görüşe göre artık, temel güç ve otorite kaynağı küresel sermayenin elindedir. Küresel sermayenin temel güdüsü kardır. Teknolojik ilerlemeler ve iletişim devriminin avantajlarından faydalanan küresel sermaye, ulus-devletin sınırlarını hiçe sayarak, karını maksimize etme amacıyla tüm yerküreyi nüfuz alanı olarak görmektedir (Bayar, 2008:32).

Dönüşümcüler: Dönüşümsel tezi savunanlar Rosenau, Giddens, Scholde ve Castel'dir. Modern toplumları ve dünya düzenini şekillendirecek sosyal, ekonomik, politik değişimlerin merkezindeki itici güç olarak küreselleşmeyi görmektedirler. Küreselleşme tahmin edilemez ve belirsizdir. Dolayısıyla aşırı küreselleşmecilerin ve küreselleşme karşıtlarının yön tayin etme, gelecek hakkında fikir belirtme ve harita çizme gibi öngörüde bulunmalarının aksine dönüşümcüler herhangi bir tahminde bulunmamaktadırlar. Küreselleşmenin şekillenmesinde konjonktürel faktörler olduğunu, çelişkiler barındırdığını ve uzun dönemli bir süreç olduğunu iddia etmektedirler. Ulus devletin sonunun geldiğini ya da hiçbir değişiklik olmadığını savunanların aksine yapısının dönüştüğünü ileri sürmektedirler (Cebeci, 2011:373).

\section{Küreselleşme Kavramları Bağlamında Türk Futbol Kültürü}

Dünyanın en büyük siyasi organizasyonu olan Birleşmiş Milletlere üye ülke sayısı 193 olurken, FIFA'ya kayıtlı üye ülke sayısı 211 olarak karşımıza çıkmaktadır. Tek başına bu sayı bile futbolun küresel olarak nerede durduğuna dair önemli bir gösterge niteliği taşımaktadır. Futbol artık günümüzde karşı konulmaz bir fenomen olarak ön plana çımıştır. Kıtalardan ülkelere, gruplardan bireylere, ekonomiden kültüre, teknolojiye kadar birçok alanı etkilemekte ve birçok alandan etkilenmektedir.

Boniface (2007)'e göre futbol, küreselleşmenin son evresidir "Günümüzde futboldan daha küresel bir olgu yoktur. Bu imparatorluk öyle bir durumdadır ki ona direnebilen en küçük bölge bile kalmamıştır. Ancak bu imparatorluk zorla isgal eden değil, davet edilen bir efendidir. Tipik Britanya sporu dünya sporu haline gelmiştir". Boniface'in yorumu biraz abartılı olsa da futbol, ekonomisi, tüketim ürünleri, yıldızları, takımları ve taraftarlarıyla küreselleşmenin en görünür alanlarından biri olmuştur.

Futbolun İngilizler tarafindan bulunduğu genel olarak kabul olan bir gerçekliktir. Fakat futbolun tarihsel başlangıcı için M.Ö. 3000'li yıllara kadar gitmek gerekmektedir. Çinliler bahsi geçen yillarda futbola benzeyen, topla bir oyun oynuyorlardı. Ancak bugünkü anlamda modern futbol İngilizler tarafindan kurumsallaştırılmıştır. 1863'te 11 kulüp, modern futbol kurallarını ortaya koyup İngiltere futbol birliğini (F.A) kurmuşlardır. Daha sonra, İskoçya'da 1873 'te, Galler'de 1876 'da, İrlanda'da 1880'de kurulmuştur. Britanya dışında kurulan ilk futbol federasyonları, Belçika (1895), İsviçre (1895), Danimarka (1899), Hollanda (1899), Almanya (1900) (Akkaya, 2008; Boniface, 2007: 16).

1800 'lerin son çeyreğinden itibaren futbol önce İngiliz sömürgelerine daha sonra ise dünyanın diğer bölgelerine doğru hızla yayılmaya başlamıştır. 1930'lara kadar olan dönemde yayılma kara yolları, deniz yolları aracılığıyla gerçekleşmiştir. Radyonun daha sonra da televizyonun gelişmesi ile birlikte yayılma devasa boyutlara ulaşmıştır. 1966'da Dünya Kupası ilk kez canlı olarak yayınlandığında iki milyar seyirci tarafindan izlenmiştir (Boniface, 2007: 21).

Türkiye'de futbol ve kültürünün gelişimi Geç Osmanlı ve Erken Cumhuriyet dönemi spor politikasına -önemli ölçüdebağlı olarak hızlı gelişim gösterememiş̧ir. Dünyanın belli bölgelerinde de olduğu gibi amaç sağlıklı insanlar yetiştirmek, her an savaşa hazır olmaktır. Sovyetlerin Vsebolus teşkilatı, Slavlar Sokol sistemi; Almanların, Fransızların, İsviçrelilerin jimnastik uygulamalarının amacı sağlıklı ve asker millet sistemini oluşturmak olmuştur (Akın, 2004).

Modern anlamda Türk spor anlayışı -halk sağlığı, eğitim sistemleri, refah uygulamalar1- II. Mahmud döneminde başlamış ve devam etmiştir. Bu mirası İttihat ve Terakki ve Cumhuriyeti de devam ettirmiştir. Erken Cumhuriyet dönemi boş zamanı eğlencede değil faydalı değerlendirme, sağlıklı bedenler yetiştirme ve en önemlisi "yeni adam"ıkurgulama projesi olarak görmüştür. Yeni adam: uysal, sağlıklı, verimli, savaşa karşı sürekli teyakkuz halinde, devrimleri benimsemiş adamdır. Bu Kemalizmin rekabetçi, saldırgan sporun yerine; faydacı, işe yarar, geliştirici sporun gelişimini önemsediğinin 
göstergesidir. Futbolun doğasında var olan gruplaşma, zamanı boşa harcama, rekabet, rakibini yenilgiye uğratma gibi birlik beraberliğe ters yapısı ve "yeni adam"la uyumsuzluğu nedeniyle, devlet tarafından diğer sporların gerisinde değerlendirilmiştir. 1951 sporda profesyonellik kanununa kadar devam etmiştir (Akın, 2004).

19. yüzyılda spor, ulusal sınırla içerisinde halkı savaşa hazır tutmak, zindeliği sağlamak, millet-i müsellaha (silahlı millet) gibi amaçlar doğrultusunda yaygınlaştırılırken; sömürgeci ülkelerin ulusal sınırları dışında ideolojik meşruiyetini sağlama, yerli halklarla iletişimi sağlama, çatışmayı azaltma gibi hegemonik amaçlar için küre çapına yayılmaya çalışılmıştır.

1960'lara gelindiğinde daha önceleri iftihar vesilesi olan güreş, artık yerini yavaş yavaş futbola bırakmaya başlamıştır. $\mathrm{Bu}$ tarihlerden itibaren futbol ligleri Anadolu'ya yayılmaya yönelmiştir. Futbol, iyi kötü bilinçli bir siyasallaştırılmanın, ideolojikleştirilmenin sürecine girmiştir. Tribündeki seyirci, epey öne çıkmış, göstergeler, semboller, tribünlerde nasıl bir siyasal dil oluşturuyor, bunlar analiz edilmiştir (Kurt ve Atayman, 2008: 398).

Günümüzde ise tüm dünyada futbolun, spor olgusunun da önüne geçmekte olduğu görülmektedir. Âdeta hayatın yoğunlaştırılmış bir hali gibi görünen bu oyunda, insanlar yaşamları içinde adını koyamadıkları pek çok şeyin yansımasını bulmaktadırlar. Biraz da bu nedenle "futbol, artık sadece futbol değildir" (Kuper, 2014) kanaati ağır basmaktadır (Talimciler, 2008: 90).

Küreselleşme ve futbol arasındaki yakın ilişki, sosyal bilimcilerin dikkatinden kaçmamıştır. Fakat küreselleşme denildiğinde genellikle küreselleşmenin ekonomik yönü vurgulanmış, kültürel alan büyük ölçüde ihmal edilmiştir. Bu anlamdaRobetson ve Gilluanotti küreselleşmenin kültürel yönüne ve futboldaki kültürel yansımalarına eğilmişlerdir. Küresel futbol kültürünü anlamak adına "küresel süreçler teorisi"yle, yerel ve küresel süreçlerin birbirine olan bağımlılığını ortaya koymaya çalışmışlardır. Küresel süreçleri teorisi iki bağıntılı süreçten meydana gelmektedir. Birincisi küreselleşme, dünyanın tek bir yer olduğuna dair artan farkındalık olurken; ikincisi küyerelleşme olarak tanımlanmaktadır. Yani yerel kültürlerin herhangi bir küreselyerel bir ürünün kendi ihtiyaçları, inançları ve gelenekleri bağlamında adapte edilmesi ve yeniden tanımlanmasıdır (GiluanottiveRobertson, 2004: 546).

\subsection{Küyerelleşme}

Küyerelleşme, küreselleşmenin tek yönlü olduğu tezine karşılık, yerelliği dikkate alan, yereli değiştiren, yerelle birlikte dönüşen, yeni formlar üreten kapsamlı bir süreci ifade etmektedir.

Küyerelleşme, son yıllarda oldukça sık kullanılan kavramlardan biri olarak dikkat çekmektedir. Küyerelleşme, küreselleşme ve yerelleşmenin bakış açılarını da alarak, yaşanılan sürecin tek başına yerelleşme ya da küreselleşmeyle açıklanamayacak kadar çok dikotomiler, çeşitlilikler, farklılıklar, zıtlıklar, uyma ve uyum sağlama (adaptation), kabul etme ve sahiplenme (adoptation) barındırdığını ifade etmektedir (Drori vd., 2014).

Küyerelleşme, küresel olanla yerel olanın çatışmasına bir çözüm olarak da ortaya çıkmaktadır. Küresel futbol kültürünün kabul edilmesi ya da küresel futbol kültürüne adapte olmayla birlikte, yerel olan nitelikler de bir şekilde küresel olanla ilişkiye girmektedir. Bu birliktelik bir anlamda zıtlıklara karşı bir çözüm olarak da işlev görmektedir. (Andrews vd., 2014: 261). Küyerelleşmede dikkati çeken en önemi özellik, karşılaşmaların ve karışmaların örtük veya açık bir şekilde karşılıklı anlaşmaya dayanmasıdır.

Küreselleşme zaman ve uzamla uyum sağlayarak yayılmayı hızlandırmıştır. Daha açı ifadeyle küresel olan futbol kültürü öncelikle kendi kültürüyle gelmiş ve bir süre sonra yayıldığı coğrafyalarda yerel kültürleri de içine alarak farklı formlar geliştirmiştir. Daha sonra küyerelleşme ile birlikte yerel uzam ve zamanda tutunmaya başarmıştır (Jijon, 2013: 385). Futbolun bu kadar yaygın ve etkili olmasının altında yatan en önemli etkenlerden biri de söz konusu karşılıklı rıza olarak ortaya çıkmaktadır.

Futbolun küresel yayılımı farklı türdeki kültürel küyerelleşmelerle kendini göstermektedir. Bunlardan ilki, futbol küresel olarak yayılmaya başladığı dönemlerde, bazı kültürleri ya reddetmiştir ya da radikal bir şekilde dönüştürmüştür. Örneğin Asya'nın belli bölümleri futbol yerine kriketi tercih etmiştir. Avusturalyalılarsa kendi futbol kodlarını oluşturmuşlardır. Amerika'da ise kendi mahallelerine uygun bir şekilde bir futbol yorumu getirmişlerdir (Robertson ve Giluanotti, 2004: 550). Ancak tüm bu yerel etkiler, küresel anlamda futbolun dinamikleri üzerinde kayda değer bir etkide bulunmamıştır.

Futbolun ikinci küyerelleşme biçimi ise, belirli yerel kültürler futbolun evrensel kuralları içinde kendi futbol geleneklerini oluşturmaları ile göz önüne çıkmıştır. Oynama sitilleri, taktikler, estetik kodlar bu geleneklerin içinde oluşmaktadır (Giluanotti veRobertson, 2004: 550).

Üçüncü olarak 1920'ler ve 60'lar arasında evrenselliğin tikelleşmesi şeklinde gerçekleşen uluslararası turnuvalar ve farklı yönetsel yapılar kurulmuştur. Özellikle 1920 yılında Belçika'nın Atwerp kentinde toplanan Uluslararası Futbol Federasyonunun genel kurul toplantısında futbol kurallarının evrenselleştirilmesi noktasında aldığı kararlar, evrenselliğin tikelleşmesinde önemli rol oynamıştır. Futbolun kıta yönetimleri bu tarihler arasında kurulmuştur. Dünya kupası karşılaşılmaları 1930, Avrupa Kupası 1955, Kupa Libertadores 1960'ta başlamıştır (Giluanotti veRobertson, 2004: 550; Öngören ve Karadoğan, 2002: 216).

Dördüncü olarak 1960'ların sonundan itibaren küyerelleşme daha yoğun akışlar ile şekillenmiştir. Uluslarötesi çalışan bilgi, sermaye ve meta sirkülasyonu kültürel tikelliğin ulusal olmayan formlarını inşa etmiştir. Uluslar veya kıtalar arasında çok az taktik ve estetik farklılık söz konusu iken; uluslar kendilerini başarılı rekabetlerde görelileştirmeye çabalamaktadır. Taraftar kültürleri lokalliğin veya bir ulusun sunumunda önemli bir rol oynamaktadır. Yine de futbolun içinde daha kozmopolitan, kendini dünya vatandaşı olarak gören taraftar profiline rastlayabilmek de mümkün olabilmektedir (Giluanotti veRobertson, 2004: 550).

Robertson ve Giluanotti futbolun büyük ölçüde küreselyerelleşmiş olduğu ve bu küyerelleşmenin de sporun küreselleşmesine ilişkin değerlendirmeler için en iyi anlayış olduğu kanaatini taşımaktadırlar (Ritzer, 2011: 289). 


\subsection{Evrensel-Tikel İlișkisi}

Evrensel ve tikel (yerel) ilişkisi, yaşadığımız dönemin kültürel dönüşümünü anlamak ve adlandırmak adına önem arz etmektedir. Evrensel kurallar, yerel dinamiklerle bir şekilde ilişki kurmakta ve bu ilişkiyi devam ettirmektedirler. Futbol kültürü evrenseldir fakat bu evrenselliğin, tikelden tümüyle ilişkisiz olduğunu ileri sürmek mümkün görünmemektedir.

Futbol kültürünün temel dayanak noktası, evrensel ve tikelin ilişkisine dayalı olarak ortaya çıkmaktadır. Herhangi bir tikel sosyal sürecin, evrensel olanın aracılı̆̆ıyla anlaşılması gerekmektedir. Küreselleşme, tüm özgüllüklerle bağlantı kurmaktadır. $\mathrm{Bu}$ yönüyle küreselleşme, belirli inançları, özellikleri, yerellikleri küresel alanda karşı karşıya getirmekte, evrensel alanda tanımlamaktadır. Sonuç olarak küreselleşme, yerelliklerle kategorik olarak karşıtlık içinde gibi gözükse de birbirleriyle iç içe geçmiş bir yapı sergilemektedir (Giluanotti ve Robertson, 2004: 547)

Futboldaki karşılıklı bağımlılık, iki anahtar kavram aracılığıyla gelişmektedir. $\mathrm{Bu}$ kavramlardan ilki özgüncülüğün/tikelciliğin evrenselleşmesidir. Bu sayede tikel olan evrenselleşmekte, yeni benzersiz kimlikler, formlar ortaya çıkmaktadır. Örneğin modern ulusların ve kimliklerin ortaya çıkışı ile uluslararası ekonomik ve sosyal sistemin önemli oranda ilişkili olduğu bilinmektedir. Bu bağlamda uluslararası futbol turnuvaları ya da diğer kültürel yarışmalarda bireylerden beklenen; bireylerin etnik kimliklerinin üzerinde bir milli takımın üyeleri olmalarıdır. Büyük uluslararası turnuvalarda binlerce insan, taraftar grubu takımlarını desteklemek için bir araya gelmektedirler. $\mathrm{Bu}$ birlikteliklerde her milletin kendine ait dansları, şarkıları, görsel şovları, kıyafetleri sergilenmektedir. Böylece küresel görecelilik, küresel olan oyunu küyerele dönüștürmektedir (Giluanotti ve Robertson, 2004: 547). 2016 Avrupa Şampiyonası'nın dikkat çeken takımlarından biri olan İzlanda tikelin evrenselleşmesi sürecine önemli bir örnek teşkil etmektedir. İzlandalı taraftarların turnuva boyunca giderek sıklaşan aralıklarla alkışlama olarak tarif edilebilecek Balina Çağırma tezahüratı çok ilgi çekmiş ve hemen diğer takım taraftarları tarafindan taklit edilen bir tezahürat olmuştur. Hatta böyle bir tezahüratın kendi kültürel taraftar kimlikleri ile uyuşmadığını düşünen bazı gruplar bu tezahürata karşı çıkmışlardır (www.haberler.com).

İkinci olarak ortaya çıkan sonuç birincinin tam tersidir. Evrenselin tikelleşmesi (yerelleşmesi) olarak adlandırılabilecek bu durum, yerel olanı evrensele bağlamıştır. Bunu da ulusları belirli düzenlemelerle küresel bağın halkalarına ekleyerek gerçekleştirir. Örneğin uluslararası hukuki çatılar, dünya saat bölgeleri, takvimler bu bağlantıyı gerçekleştirmeye yönelik girişimlerdir (Robertson, 1999). Futbolda küresel yönetim biriminin başında FIFA yer almaktadır. Bunu takiben kıtasal yönetim organları, ulusal, bölgesel ve yerel dernekler, futbol kulüpleri bulunmaktadır. Özellikle futbol kulüpleri, uluslararası futbol yönetim organlarının temel ilke ve biçimlerini temsil etmektedirler. Bütün uluslar dünya futbol takvimine göre hareket etmektedirler. Her ülkenin standart ligleri bulunmaktadır. $\mathrm{Bu}$ ligler, FIFA'ya bağlıdır ve onun standartlarına göre hareket etmektedir (Giluanotti veRobertson, 2004: 548; Ritzer, 2011: 287). Buna göre dünyaca ünlü Barcelona futbol kulübü de alt liglerde oynayan herhangi bir kulüp de aynı kurallar ile muhatap olmaktadır. Bu kurallardan en önemlisi, Finansal Fair Play (FFP) olarak ifade edilen ve tüm kulüplerin gelir gider dengelerini sağlamayı amaçlayan kurallar bütünüdür. Bu kuralları karşılayamayan takımların uluslararası turnuva ve yarışmalara katılımı engellenmekte, bütçe sinırlandırmaları ve transfer yasakları gibi yaptırımlar gündeme gelmektedir. Yerel olanın evrensele bağlanması, bu kural ve kaideler bütünüyle saptanmaktadır. Artık futbol kulüplerinin sahipleri veya başkanları değiştiğinde yeni atılımlar yapmaları oldukça kısıtlı bir hale gelmiştir. Gelirleri arttırıcı formülleri zorlayan bu evrensel yapı, yerelde söz konusu gerekliliklere yönelik çözüm yollarının aranmasını gündeme getirmiştir.

Futbolda yerel ve küresel arasındaki kültürel değişimler tek yönlü değildir. Toplumlar, küresel kültürel içeriğin pasif alıcıları değildirler. Futbol aynı zamanda yerel kültürlerin, yeni tikellik formlarını keşfetmesini de sağlamaktadır. Örneğin topluluk kulüpleri kurmak veya belirli oyun sitilleri geliştirmek gibi. Yerel kültürlerin kültürel eylemler, kimlikler, ürünler ve topluluklar ile bağları zayıflamaktadır fakat bu zayıflama, yeni alanlar oluşturabilmektedir. Bireyler ve gruplar, anlamsız kültürel karışımlar meydana getirmek yerine, yeni alanlar oluşturmakta ve yerelleşmiş kültürel kimlik hissiyatları oluşturmaktadırlar. Örneğin Liverpool futbol kulübü ezeli rakibi olan Manchester United'a göre daha güçlü yerel bağlara işaret eden bir kültürel kimliğe sahipken, 1970'lerden sonra ulusal ve dünya çapındaki başarıları, bu özelliğinin değişmesini beraberinde getirmiş̧ir. 1990'ların sonundan itibaren kulübün sahipliği iki Amerikalı girişimciye geçmiştir. Bir diğer örnek İrlanda milli takımıdır. İrlanda milli takımını oluşturan futbolcular, İrlanda vatandaşları ve İrlanda Diasporasının çocuklarından oluşmaktadır. İrlanda başbakanı bu durumu modern İrlanda olarak tanımlamaktadır (Giluanotti veRobertson, 2009: 34).

Günümüzdeki tüketicilik, ulusal kimliklendirmenin farklı formlarını ön plana çıkarmaktadır. İngiltere'de Brezilya forması; Türkiye'de Fransız forması satılabilmektedir. Dünyanın farklı bölgelerinde örneğin Türkiye'de Arsenal tamının taraftarları bulunabilmektedir. Farklı sosyal gruplar, küresel oyunun içinde yerelin anlamını tartışmakta her grup yerelin anlamını kendi dünyasına göre yorumlamaktadır. İngiliz için Manchester United takımının yerelliği, Norveçli için yerellikten farklı anlamlar taşımaktadır.

\subsection{Homojenleşme, Heterojenleşme, Melezleşme}

Küreselleşme hakkında belki de en yaygın inanç kültürel özellikler ile pratiklerin birbirine yaklaşması olarak ortaya çıkmaktadır. Günlük hayattan örnek verilecek olursa, Singapur, St. Louis ya da Sao Paulo'daki bir alışveriş merkezi ya da bir otel birçok benzerlik taşıyabilmektedir. Dünyanın Coca Colalaşmasıya da McDonaldlaşması gibi kavramsallaşmış terimler, küresel kültürün küresel ekonomiyi takip ettiği inancını yansıtmaktadır. $\mathrm{Bu}$ bağlamda homojenleşme, Batılılaşmayla daha da özelde Amerikanlaşmayla aynı anlamda kullanılmaktadır. Bu bakış açısından, değişim mekanizmaları piyasa ekonomisi ile çok uluslu şirketlerin küresel stratejilerinin dünya çapında yaygınlaştırılması ile ilişkilendirilmektedir (Holton, 2013: $62)$. 
Homojenleşme, Amerikanlaşma ve Batılaşma kavramlarıyla ele alınmaktadır. Homojenleşmede yüksek oranda tek yönlü, merkezden çevreye doğru asimetrik bir akış söz konusu olmaktadır (Giluanotti veRobertson, 2009: 3940). Kültürel çakışma olarak adlandırdı ğı homojenleşme tezine göre, kültürler benzer küresel akıntılara tabidirler ve giderek daha fazla benzeşmektedirler. Buna göre dünya kültürleri giderek ya da en azından belli ölçülerde ve bazı bakımlardan benzer hale gelmektedirler. Küresel asimilasyon dünyadaki hâkim gruplar ve toplumlardan yana gelişmektedir. Egemen kültürün yaygınlaşması standart hale gelmiş kültürel modellere ve dünya çapında örgütsel eşbiçimciliğe yol açmıştır. Bunların hepsi giderek artan küresel homojenliğin "yumuşak" modelinin bir parçası haline gelmektedir (Ritzer, 2011).Örneğin Türkiye'de ve dünyanın birçok bölgesinde İngiltere liginin izlenmesi bu homojenleşmenin bir göstergesi olarak gündeme gelmektedir.Egemen kültürün yaygınlaşması olarak hakim grup ve toplumların kültürel çıktılarının daha fazla kabul görmeye başlaması futbol üzerinden okunabilir bir durumu arz etmektedir. Büyük turnuvaların (Dünya Kupası veya Avrupa Futbol Şampiyonasi) tüm dünyada izleniyor olmasinın yanı sira bu turnuvalara katılan takım sayısının giderek arttırılıyor olması da futbol kültürünün dünyanın her yerine taşınmasına olanak sağlamaktadır.

Sermaye gibi dolaşım sınırları ortadan kaldırılmış futbolcuların "küresel" hareketi, "ulusal" futbol, ülkeye özgü futbol kimliği vb. tanımları da zorlamaya başlamıştır. Paranın küresel sınır tanımaması gibi, oyuncuların da ulusal sınırlardan kolayca geçmeleri, ulusal takım vurgusunu ve arayışını da zora sokmuştur (Kurt ve Atayman, 2008: 399). Geçmiş yıllarda yabancı futbolcu transferinin önünde oldukça ciddi engeller bulunmaktaydı. Yabancı futbolcu oynatma konusunda sayı sınırlamaları söz konusu olmaktaydı. İktisadi anlamda "korumacılık" olarak bilinen anlayışa benzer bir anlayış daha ağır basmaktaydı. Bu konuda verilebilecek en biline ve en uç örneklerden biri ise 1960 yılında Brezilya hükümetinin, Pele'yi milli servet ilan ederek ülke dışında futbol oynamasına engel olması olarak gösterilebilmektedir. Ulus devletlerin çağdaş uygulamalarına bakıldığında ise bu tür korumacı nitelikteki engelleri büyük ölçüde yürürlükten kaldırmış ve daha liberal bir anlayışa yönelmişlerdir. Bu da, dünya genelinde oynanan futbolun giderek benzer hale gelmesine kaynaklık etmiştir.

Homojenleşmenin yanı sıra, heterojenleşmenin varlığına yönelik olarak da birçok görüş ve uygulama örnekleri ortaya çıkmış bulunmaktadır. Küresel kültüre; kutuplaşma yaklaşımı, çağdaş dünya ile ilgili birbiriyle ilişkili argümanlar ileri sürmüştür. Yaklaşımın sadeliği sayesinde birçok yorumcu bu konuda ikna edilebilmiştir. İleri sürülen kanıtlar da bu görüş ile tutarlılık sergilemektedir. Olayları homojenleşme yerine kutuplaşma üzerinden düşünüldüğünde birçok ilginç konu gündeme gelmektedir. Değinilmesi gereken hususlardan biri, Batılı küreselleşmenin kültürel dirençle karşılaşıp sınırlandırılmış olmasıdır. Az araştırılmış olan ikinci konu ise, bu direncin doğası ile ilgilidir. Bu direnç birçok çalışmada çoğu kez ileri sürüldüğü gibi, savaşan kabileler içindeki parçalı küresel kültüre hizmet eden bir çeşit anti-globalizm midir? Yoksa Huntington'un bir tür alternatif küreselleşme olarak gördüğü Batılı liberal demokrasiye meydan okuyan İslami-Konfüçyan eksen oluşumu mudur?
Ve tüm bu tartışmalar içinde Afro-sentrizm veya Panislamizm gibi kapsam bakımından küreselden az ulusaldan fazla olan hareketlerin nereye yerleştirilmesi gerektiği şeklindeki soru da gündemdeki yerini korumaktadır (Holton, 2013: 68).

Heterojenleşmenin futboldaki görünümü, Giluanotti ve Robertson'a (2009) göre hem çatışmayı hem de yaratıcı etkileşimi içinde barındırmaktadır.Bu anlamda heterojenleşme; yaratıcı etkileşim (creolization), yerlileşme (indigenization) veya yerelleşme (vernacularization) olarak ortaya çıkmaktadır. Yaratıcı etkileşim bir anlamda modern olanla yerel olanın etkileşimidir. Arjantin futbolu; Gine yerlilerinin futbol maçları fikstürünü takip eden günlere koyarak kaybeden takımlara yenmek için imkân tanımaları; Asya'daki futbol kültürü ve pratiklerinin (konsensüs, düzenlilik ve kibarlık) farklı olması; Güney Amerikalıların röveşata'yı bulmaları ve bunun Avrupalılar tarafından taklit edilmesi buna örnektir. Türk futbolunda bu tür bir yaratıcı etkileşim olarak halı saha futbol kültüründen bahsedebilmek mümkündür. Dünyanın diğer bölgelerinde profesyonel olmayan oyuncular futbolu; çim saha, spor salonları (futsal) veya toprak sahalarda oynamaktadırlar. Türkiye de ise bir yaratıcı etkileşim sonucu halı sahaların çok geniş bir kabul gördüğü ve 16-50 yaş arası şehirli Türk erkeklerinin haftalık yaşam pratiklerinde halı sahada futbol oynamanın yeri olduğu söylenebilir (Kıvanç,2014:387). Halı saha kültürünün bu denli yaygın ve kabul edilmiş olması henüz Türk futbol kültüründe kendine has bir futbol oynama stiline evirilmemiştir. Buradan hareketle halı saha kültürünün oyunun oynanma biçimlerinde bir farklılık oluşturmaktan ziyade, oyununun oynanabilir hale gelmesini sağlayan araçlarda bir farklılık olarak göze çarpmaktadır.

Heterojenleşmenin bir diğer görünümü olarak yerlileşme kavramı, merkez-ilişkilerine daha kültürel politik açıdan bakmaktadır. Yerelleşme, genel kültürel formlarda ortaya çıkan yerelleşme söylemini ifade etmektedir. Örneğin Hintliler kriketi yerelleştirerek Hint milliyetinin bir amblemi haline dönüştürmüşlerdir. Batı Avrupalı etnik azınlıkların, Güney Avrupa ve Avustralya'da kurdukları futbol kulüplerinin milliyetçi ya da bölgeselci kimliklere sahip olması, yerlileşmeyi göstermesi açısından önem arz etmektedir. Türk futbol kültürü bağlamında değerlendirildiğinde,heterojenleşmenin farklı görünümleri olarak ifade edilen küreselleşme kavramlarından yerelleşme veya yerlileşme örneklerinin varlığından kısmi olarak bahsetmek mümkün olabilmektedir. Trabzon'un, Bursa'nın veya Ankara'nın yerel ve özgün tribün, taraftar ve futbol kültürleri söz konusudur fakat bu kültürler küresel dinamiklerin etkisinden çok yerel, bölgesel veya ulusal rekabet ortamında ortaya çıkmış ve genel olarak İstanbul kulüpleri ile belirli bir düzeyde tansiyon, karşıtlık ve rekabet taşıması ekseninde şekillenmiştir. $\mathrm{Bu}$ karşıtılık elbette Anadolu kulüpleri ve üç büyüklerin taraftar grupları, kültürleri arasında hiçbir şekilde benzerlik olmadığı anlamına gelmemelidir. Anadolu kulüpleri de önemli ölçüde büyüklerden etkilenmektedir. Ancak bu etki beraberinde çatışmayı da getirmektedir.

Homojenleşmenin bu denli yaygınlaştı̆̆ı futbol endüstrisinde, heterojenleşme anlamında geleneksel bir futbol sitiline sahip olmak, yalnız başına yeterli olmamaktadır. Benzer olmasa da farklı bir yerel futbol kültürü olarak 
İspanya'nın Bask bölgesi temsilcisi Athletic Bilbao futbol takımı, özgün bir örnek teşkil etmektedir. Bir kural olarak sadece Bask bölgesi doğumlu oyuncuların takıma alındığ Athletic Bilbao, kendi futbol kimliğini ve kültürünü koruma çabasında olan bir futbol kulübü olma özelliğini taşımaktadır. $\mathrm{Bu}$ homojenleşen yapı içinde hem kendine has olma durumunu koruyan hem de yarışmacı niteliğini devam ettiren bir takım olması ilgi çekicidir. Elbette ki bütün takımların durumunun sadece bu süreçler ile açıklanması mümkün gözükmemektedir. En iyimser söylemle, söz konusu temellere dayalı olarak yapılan açıklamalar, eksik pek çok yön barındırmaktadır. Fakat bu, homojenleşmeheterojenleşme süreçlerinin günümüz futbolunun içinde bulunduğu durumu açıklamada payının olmayacağı anlamını taşımamaktadır.

Homojen-heterojen tartışmasını, bir başka yerel futbol kültürü olarak dikkat çeken Altınordu Futbol Kulübü üzerinden yapabilmek mümkündür. Son yıllarda Altınordu Futbol akademisinden çıkan oyuncuların Almanya ve İtalya gibi önemli liglere genç yaşlarda transfer yapmış olması (Çağlar Söyüncü, Freiburg ve Cengiz Ünder, Roma) bu kulüpteki yapılanmanın ve yürütülen uygulamaların homojenleşen küresel futbol kültüründe bir karşılığının olduğunu göstermektedir. Altınordu, aynı zamanda heterojenliğini koruyan bir futbol kulübü olarak da dikkat çekmektedir. Bu anlamda kulüp, iş yapma biçimlerini hem küresel standartlara uydurma çabasında hem de yerel ve kendine özgülüğünü yitirmeme kaygısını taşımaktadır. Futbol altyapılarında yer alan öğrencilerine futbol eğitiminin yanında kültürel programlar, bahçecilik ve köy hayatı ile ilgili öğrenim süreçlerine de yer verilmesini, bu çabanın olumlu örnekleri olarak ifade edebilmek mümkündür (www.altinordu.org).

Heterojenleşmenin bir boyutu olarak ya da kendi başına müstakil bir kavram olarak melezleşme tezi, küreselleşme bağlamında gündeme gelen kavramlardan bir diğeridir. Melezleşme (hibritleşme) tezi, kültürlerarası değişim ve çeşitli kaynaklardan doğan kültürel unsurlar arasındaki ortaklığı merkeze almaktadır. Biyolojik hibritlerin farklı kaynaklardan genetik materyali bir araya getirilmesine benzer olarak hibrit sosyal pratikler de farklı kaynaklardan gelen kültürel unsurları birleştirmektedir. Homojenleşme ve kutuplaşmanın önemi kabul edilse bile, bu iki durum, küresel kültürü oluşturan karmaşık ve çok boyutlu unsurları açıklamada tümüyle yeterli görünmemektedir (Holton, 2013: 72). $\mathrm{Bu}$ perspektifte ağırlı noktası, süregelen küresel homojenleşmeye değil de heterojenleşmeye işaret eden yeni ve farklı melez biçimleri üretmek için çeşitli yerel gerçeklikler üzerinde yer alan küresel süreçlerin bütünleşmesine kaymaktadır. Melezleşme, pek çok farklı yerellikte artmasa da devam eden, yeni kültürel gerçeklikleri ortaya çıkaran derinlemesine yapılandırıcı bir süreç olması nedeniyle, küreselleşmedeki son derece olumlu hatta romantik görüşü ifade etmektedir (Ritzer, 2011: 272).

Futboldaki görünümleri açısından melezleşme zengin bir yap1 sunmaktadır. Uluslararası büyük futbol kulüplerinin farklı ülkelerdeki taraftar gruplarının bir nevi melez futbol taraftarlığı ve kültürü ortaya koyduğunu ifade edebilmek mümkündür. Buna göre hayatında hiçbir zaman Arsenal futbol takımını Londra'da izlememiş olan bir Türk Arsenal taraftarı bir araya geldiği akranları ile beraber yeni ve melez bir taraftar kültürünün oluşmasına zemin hazırlamaktadır. Takımın kupalar kazanıp kazanmaması ile daha az ilgili olup, futbol kültürüne ve karizmatik oyuncularına daha fazla öykünmek gibi durumlarla daha sık karşılaşılacak bu tür melez futbol taraftarlığında asıl vurgu, yerel kültürden farklı olma isteğinden ileri gelmektedir.

Bir diğer melezleşme ise futbol kulüplerinin ritüelleri, pratikleri ve iş yapış şekillerini oluştururken kurdukları hibrit yapılar olarak belirginleşmektedir. Örneğin Fenerbahçe'nin iç saha maçlarında takımın sahaya çıkışı öncesi çalınan bir müzik ve yapılan karşılama ritüeli, tipik bir melezleşme örneği olarak ortaya çıkmaktadır. 1992 yapımı "Son Mohikan" isimli bir Holywood filmi ile bilinirliği artan müzik parçasının çalınması ile taraftarların, atkılarını ileri geri sallayarak yaptıkları takım karşılama ritüelleri hem küresel hem de yerel öğeleri birlikte içermektedir. Bu hibrit yap1, taraftarların birlikte hareket ettikleri, güzelliği ile övündükleri ve stadyumdaki taraftarın katılımcı kimliğini geliştiren bir öğe olarak dikkat çekmektedir. Futbol takımının veya kulübün kendine has ve özel olarak bestelenmiş farklı marşlar, ezgiler veya şarkılar varken küresel anlamda tanınırlığı olan müziğin, stat ritüelinde kullanılması, melezleşme örneği teşkil etmesi bakımından dikkat çekici bir nitelik taşımaktadır. Benzer bir örnek Eskişehirspor'un en çok bilinen marşlarından "Tükenmiş Nefeslere" marşıdır. Marş İsviçreli pop grubu olan Kadebostany'nin "Walkingwitha Ghost" şarkısının bestesinden türetilmiş ve oldukça beğeni kazanmıştır. Bir diğer örnek ise yine Eskişehirspor'un resmi marşı olarak kabul edilen, her maç öncesi Bandoeses tarafından çalınan, İspanyol halk ezgisi olan "EspañaCañí" marşıdır. İsviçreli bir grubun, İspanyol halk ezgisinin Türk taraftarları tarafindan kabul edilip, takım marşıolarak benimsenmesi, futbol kültürü açısından hem küreselleşmenin hem de melezleşmenin etkilerini göstermektedir.

\section{Sonuç ve Tartışma}

Küreselleşme, reddi mümkün olmayacak kadar hayatın her alanını etkileyen, dönüştüren bir süreç olarak gündem işgal etmektedir. Süreç olması münasebetiyle, belirli bir başlangıç ve sonunun belirlenebilmesi oldukça güç görünmektedir. Küreselleşme, her tür yaklaşımın, kendi tezlerini kabul ettirmeye yönelik veriler bulabildiği bir olgudur. Bu anlamda tek bir yaklaşımı baz almak yerine belli ölçülere riayet ederek, geniş kapsamda bir değerlendirme yapmak daha makul olmaktadır.

Küreselleşme, şüphesiz ekonominin önemli oranda etkili olduğu bir fenomendir fakat bu durum kültürel, siyasal boyutunun olmadığı anlamına gelmemektedir. Robertson'un da itirazı da işte tam bu noktada yükselmiş ve küreselleşmenin kültürel boyutunun ne kadar önemli olduğunu, yapmış olduğu bilimsel çalışmalarla kanıtlamıştır.

Futbol küreselleşmenin kültürel sonuçlarının en derinden ve yaygın olarak hissedildiği alanların başında gelmektedir. Dünyanın en büyük takımlarının uyması gereken kuralların aynısına son derece yerel, sinırlı mahalle takımlarının da uyması gerekmektedir. Bu durum küresel futbol kültürünün homojenliğinin derecesini göstermesi bakımından anlamlı bir gösterge niteliği taşımaktadır. Türkiye'de ve tüm dünyada futbol kulüpleri, taraftarlar, organizasyonlar ve iş yapma biçimleri küresel bir kültürün parçası olma yolunda 
ilerlemektedir. Futbol artık sadece spor veya atletik başarının söz konusu olduğu bir alan olmaktan uzaklaşmaktadır. Küresel kurallar ve düzenlemeler ile futbol kulüpleri finansal ve yönetsel alanda da başarılı olmak durumundadır. Bu küresel etki sadece futbolun yöneticilerini değil, taraftar, izleyici veya destekleyicilerini de içine almaktadır. Öyle ki artık taraftarlık sadece maçları takip etmekle ve gönül bağına sahip olmakla elde edilmekten uzaklaşmaktadır. Artık küresel olarak kullanılan medya ve iletişim araçlarında söz konusu aidiyetin dışa vurulması ve belirli kulübe özge metaların satın alınması ile taraftarlığın küresel tüketici kültürüne ilişkin noktalarında da var olmak gerekmektedir. Böylelikle küreselleşme süreçlerinin futbol hem kendisini hem de tüm paydaşlarını belirli düzeyde etkilediği ve onlardan etkilenerek değişip dönüştüğü söylenebilir.

Küresel futbol kültürünün yerelle karşılaşması ve yeni formların ortaya çıkması ise bu durumun bir diğer boyutunu teşkil etmektedir. Evrensel-yerel karşılaşması ile ortaya çıkan yeni formların niteliğinde, karşılıklı olarak mutlak anlamda eşit bir etkiden söz etmek mümkün görünmemektedir. Fakat oluşan bu yeni formların karşılıklı etkileşim neticesinde meydana geldiğinin de görmezden gelinmemesi gerekmektedir.

Küreselleşmenin bu yeni boyutu, yereli dikkate almayı zorunlu k1lmaktadır. Küresel olabilmek, yerel olan üzerine doğrudan bir baskı ve etki uygulamak yerine, daha sofistike, karmaşı, yereli de dikkate alan bir anlayış geliştirmek sayesinde gerçekleştirilebilmektedir. Günümüz küresel futbol kültürünün temelinde de bu karşılıklılık ilişkisi yer almaktadır.

\section{Kaynaklar}

Adda, J. (2005), Ekonominin Küreselleşmesi. İstanbul: İletişim.

Akın, Y. (2004). Gürbüz ve Yavuz Evlatlar: Erken Cumhuriyet'te Beden Terbiyesi ve Spor. İstanbul: İletişim.

Akkaya, C. (2008). Küreselleşme Ve Futboldaki Dönüşüm. ETHOS, 1, 4, Syf. 1-14.

Andrews, D. L.,Batts, C., \& Silk, M. (2014). Sport, glocalizationandthenewIndianmiddleclass. Journal of CulturalStudies, 17(3), 259-276.

Atasoy, B.,\&Kuter, F. Ö. (2005). Küreselleşme ve Spor. Uludă̆ Üniversitesi Ĕ̈itim Fakültesi Dergisi, XVIII (1), 1122.

Balc1, A. (2006), RolandRobertson Küreselleşme ve Kültür, Bilgi Dergisi pol.atılım.edu.tr, 02.01.2013

Bauman, Z. (2010), Küreselleşme Toplumsal Sonuçlart.İstanbul: Ayrıntı.

Bayar, F. (2008), Küreselleşme Kavaramı ve Küreselleşme Sürecinde Türkiye, Uluslararası Ekonomik Sorunlar Dergisi, mfa.gov.tr, 02.01.2013

Beck, U. (2000). What is Globalization?, Trans. Patrick Camiller. London: Polity.

Bodur, E. (2004), Küreselleşmenin Dini Alandaki Etkisi ve Ulus-Devlet, KSÜ Illahiyat Fakültesi Dergisi, Cilt 4, sayfa: 9-26

Boniface, P. (2007). Futbol ve küreselleşme. Çev. İsmail Yerguz. İstanbul: Ntv
Cebeci, İ. (2011), Küreselleşme Yaklaşımları Kapsamında Küreselleşme Sürecinin Tarihsel Değerlendirmesi, Sosyoloji Konferansları Dergisi, Mustafa Erkal Özel Sayısı, Sayı 43, İstanbul Üniversitesi Yayınları, İstanbul.

Drori, G. S.,Höllerer, M. A., \&Walgenbach, P. (2014). Unpackingtheglocalization of organization: Fromterm, totheory, toanalysis. EuropeanJournal of CulturalandPoliticalSociology, 1(1), 85-99

Ekmekçi, A. Y., Ekmekçi, R., \& İrmiş, A. (2013). Küreselleşme ve spor endüstrisi. Pamukkale Journal of SportSciences, 4(1), 91-117

Giddens, A. (2000), Elimizden Kaçıp Giden Dünya.Bursa: Alfa Yayınevi.

Giddens, A. (2012), Sosyoloji.İstanbul: Kırmızı.

Giulianotti, R.,\&Robertson, R. (2004). Theglobalization of football: a study in theglocalization of the 'serious life'. The British Journal of Sociology, 55(4), 545-568.

Giulianotti, R.,\&Robertson, R. (2009). Culture: TheGlokal Game, CosmopolitanismandAmericanization. R. Giulianottive R. Robertson (Ed.), Globalizationand Football. (ss. 31-62). London: Sage.

Hardt, M. ve Negri, A (2001). İmparatorluk. Çev. Abdullah Yılmaz. İstanbul: Ayrıntı.

Holton, R. (2013). Küreselleşmenin kültürel sonuçları. Sosyoloji Konferanslarl, (47), 59-75.

Jijon, I. (2013). Theglocalization of time andspace: Soccer andmeaning in Chotavalley, Ecuador. International Sociology, 28(4), 373-390.

Kıvanç, Ü. (2014). Seyircinin Sahaya İnişi. R. Horak, W. Reiter, T. Bora (Ed.), Futbol ve Kültürü Takımlar, Taraftarlar, Endüstri, Efsaneler (ss. 387-402). İstanbul: İletişim. Bilgi

Klein, N. (2002). No logo. Çev. Nalan Uysal. İstanbul:

Kuper, S. (2014). Futbol asla sadece futbol değildir. çev. Sinan Gürtuna. İstanbul: İthaki yayınları

Kurt, M. ve Atayman, V. (2008). Futbolda (sporda) küreselleşme söylemiyle birlikte yeni bir örgütlenme arayışının düşündürdükleri. Iletişim Kuram ve Araştırma Dergisi, 26,Syf. 397-402)

Öngören, H.,\&Karadoğan, E. (2002). Küresel tutku: futbol. Ístanbul Üniversitesi İletișim Fakültesi Dergisi, 14, Syf. 209-221.

Öngören, h.,\&karadoğan, e. (2002). Küresel tutku: futbol. İstanbul Üniversitesi İletişim Fakültesi Dergisi, 14, 209-221

Özel, H. A. (2011), İktisadi Perspektiften Küreselleşme Kavramı ve Gelişimi, Ístanbul Üniversitesi Sosyal Bilimler Dergisi, Cilt 2, Sayfa: 91-98

Özkan, Ö. D. (2011), Futbolun kültürü: spor mu, oyun mu, yoksa (hâlâ) afyon mu?. Bilgi University, PeriodicalforCulturalStudies, Vol. 2. Syf. 140-162

Ritzer, G. (2011). Küresel dünya. Çev. Melih Pekdemir. İstanbul: Ayrintı.

Ritzer, G. ve Stepnisky, J. (2014). Sosyoloji kuramları. Çev. Himmet Hülür. 9. Baskı. Ankara: De ki 
Robertson, R. (1999). Küreselleşme: Toplum kuramı ve küresel kültür. Çev. Ü. Hüsrev Yolsal. İstanbul: Bilim ve Sanat.

Sen, H. (2013). Futbolun değişen yapısı üzerine sosyolojik bir analiz. Sosyal Bilimler Dergisi. 6/1. 88-106

Talimciler, A. (2008). Futbol değil iş: endüstriyel futbol. İletişim Kuram ve Araştırma Dergisi, 26, 89-114.

\section{İnternet Kaynakları}

http://www.fifa.com/about-fifa/who-we-are/thestatutes.html Erişim Tarihi: 01.01.2017

https://www.haberler.com/taraftarlar-moldova-macindabalina-cagirma-9418748-haberi/Erişim Tarihi: 05/06/2017.

http://www.altinordu.org.tr/Haber/2831-3/YASAMINTAM-ICINDEYIZErişim Tarihi: 08/06/2017 